\title{
Caracterização e quantificação da população de fungos em área de produção de feno de capim Tifton 85, adubado com biofertilizante suíno
}

\author{
Characterization and quantification of the population of fungi in area \\ of Tifton 85 bermudagrass hay fertilized with swine biofertilizer
}

\author{
Liziane Maciel Mufatto ${ }^{\mathrm{I}}$ Marcela Abbado Neres ${ }^{\mathrm{I}}{ }^{*}$ Caroline Daiane Nath $^{\mathrm{II}}$ \\ José Renato Stangarlin ${ }^{\text {II }}$ Kácia Carine Scheidt ${ }^{\mathrm{II}}$ Lidiane Casarotto ${ }^{\mathrm{III}}$ \\ Jaqueline Rocha Wobeto Sarto ${ }^{\text {IV }}$ Samantha Mariana Monteiro Sunahara ${ }^{I I}$
}

\section{RESUMO}

\begin{abstract}
O objetivo do presente trabalho foi quantificar $e$ identificar a ocorrência dos principais gêneros de fungos, no solo, material vegetal morto, raiz e parte aérea no capim Tifton 85, adubado com biofertilizante suíno, 7 dias após o início da rebrota. As avaliações foram realizadas, durante seu desenvolvimento (15; 22; 29 e 36 dias após o início da rebrota), no momento do enfardamento e no feno, com 30 dias de armazenamento. $O$ delineamento experimental foi em blocos casualizados com parcelas subdivididas no tempo, com quatro locais de coleta no campo de produção de feno (solo, parte aérea da planta, raiz e material vegetal morto), e 6 tempos de avaliação para parte aérea da planta $(15 ; 22 ; 29 ;$ e 36 dias início da rebrota, no momento do enfardamento e com 30 dias de armazenamento) e quatro tempos de avaliação para solo, raiz e material vegetal morto (15; 22; 29; e 36 dias após início da rebrota). Na contagem e identificação dos gêneros dos fungos referentes a cada parte da planta e solo, foram calculadas as médias e essas submetidas à análise descritiva. Uma maior população fúngica foi observada no material vegetal morto e solo, predominando o gênero Penicillium em todas as partes da planta estudadas.
\end{abstract}

Palavras-chave: adubação orgânica, Cynodon spp., feno, qualidade sanitária.

\section{ABSTRACT}

The objective of this study was to quantify and identify the occurrence of the main genres of fungi soil, dead plant material, roots and shoots in Tifton 85 fertilized with swine biofertilizer, 7 days after start of regrowth. The evaluation were carried out during development (15,22, 29 and 36 days of age) at the time of baling, hay and 30 days of storage. The experimental design was randomized blocks with split plots in time sub with 4 sampling sites (soil, plant tops, roots and dead plant material), and 6 times of evaluation for aerial part of the plant $(15,22,29$ and 36 days of regrowth, at the time of baling and 30 days of storage) and 4-cycle assessment for soil, roots and dead plant material $(15,22$, 29 and 36 days of regrowth). In the counting and identification of genera of fungi belonging to each part of the plant and soil were averaged and those submitted to descriptive analysis. Greater fungal population was observed in soil and dead plant material, predominantly Penicillium in all parts of the plant studied.

Key words: Cynodon spp., hay, organic manure, sanitary quality.

\section{INTRODUÇÃO}

O capim Tifton 85 apresenta versatilidade de uso, sendo atualmente muito utilizado na forma de pastejo e feno. Durante o processo de produção do feno, que envolve as etapas de corte da planta, secagem a campo e armazenamento, grandes alterações podem ocorrer no volumoso conservado, devido à ação de fenômenos bioquímicos e microbiológicos (JOBIM et al., 2007). Segundo REIS et al. (2003), a espécie e idade das plantas forrageiras interferem para obtenção de um feno de alta qualidade, enquanto DOMINGUES (2009) ressalta que o manejo adotado na desidratação e no armazenamento interfere diretamente na qualidade químico-bromatológica e sanitária do feno, bem como na ingestão e digestibilidade da forragem

IPrograma de Pós-graduação em Aquicultura, Universidade Federal de Santa Catarina (UFSC), Florianópolis, SC, Brasil.

"Programa de Pós-graduação em Zootecnia, Centro de Ciências Agrárias (CCA), Universidade Estadual do Oeste do Paraná (Unioeste), Rua Pernambuco, 1777, CP91, 85960-000, Marechal Cândido Rondon, PR, Brasil. E-mail: mabbadoneres@yahoo.com.br. *Autor para correspondência.

IIIGraduação em Zootecnia, Centro de Ciências Agrárias (CCA), Universidade Estadual do Oeste do Paraná (Unioeste), Marechal Cândido Rondon, PR, Brasil.

IV Programa de Pós-graduação em Zootecnia, Faculdade de Medicina Veterinária e Zootecnia (FMVZ), Universidade Estadual Paulista (UNESP), Botucatu, SP, Brasil. 
(DOMINGUES, 2009). A aplicação de dejeto suíno viabiliza a produção de feno em áreas próximas à criação de suínos, devido aos menores custos em relação aos fertilizantes químicos.

Entretanto, plantas forrageiras em crescimento estão contaminadas, naturalmente, com uma ampla variedade de fungos, principalmente nos tecidos senescentes (REIS et al. 2008), e a aplicação do dejeto contaminado, aliado a condições ambientais favoráveis, poderá aumentar a população de fungos. Dessa forma, é importante reconhecer os principais gêneros de fungos que ocorrem durante o desenvolvimento e armazenamento de volumosos, pois o fornecimento com alta população de fungos patogênicos poderá comprometer a saúde dos animais, sendo capazes de induzirem efeitos carcinogênicos, hepatotóxicos e mutagênicos ao produzirem micotoxinas (FREIRE et al., 2007).

Nesse sentido, o estudo teve como objetivo avaliar a população de diferentes gêneros de fungos em área de crescimento de plantas de capim Tifton 85 , destinadas à produção de feno adubadas com biofertilizante suíno.

\section{MATERIAL E MÉTODOS}

O experimento foi conduzido em Marechal Cândido Rondon, possuindo como coordenadas geográficas latitude $24^{\circ} 33^{\prime} 40^{\prime}$ 'S, longitude $54^{\circ} 04^{\prime}$ 12 " W e altitude de $420 \mathrm{~m}$. O clima local é do tipo Cfa, subtropical com chuvas bem distribuídas durante o ano e verões quentes, conforme classificação de Köppen. Durante o período de coleta de dados (26/03/2013 a 15/04/2013), as temperaturas médias, máximas e mínimas variaram, respectivamente, entre 15,9 a $24,4^{\circ} \mathrm{C} ; 20,6$ a $32,4^{\circ} \mathrm{C} ; 7,1$ a $22,1^{\circ} \mathrm{C}$, enquanto a precipitação pluviométrica acumulada foi de $159 \mathrm{~mm}$.

O solo é classificado como: Latossolo Vermelho eutroférrico de textura argilosa (SANTOS et al., 2013) e apresentou as características químicas: $\mathrm{pH}$ $\left(\mathrm{CaCl}_{2}\right)$ 5,73; P (Mehlich) 30,64mg dm ${ }^{-3}$; $\mathrm{K}$ (Mehlich) $0,17 \mathrm{cmol}_{\mathrm{c}} \mathrm{dm}^{-3} ; \mathrm{Ca}^{2+}\left(\mathrm{KCl} 1 \mathrm{~mol} \mathrm{~L}^{-1}\right) 7,41 \mathrm{cmol}_{\mathrm{c}}$ $\mathrm{dm}^{-3} ; \mathrm{Mg}^{2+}\left(\mathrm{KCl} 1 \mathrm{~mol} \mathrm{~L}{ }^{-1}\right) 2,47 \mathrm{cmol}_{\mathrm{c}} \mathrm{dm}^{-3} ; \mathrm{Al}^{1+}$ $\left(\mathrm{KCl} 1 \mathrm{~mol} \mathrm{~L}^{-1}\right.$ ) 0,00 $\mathrm{cmol}_{\mathrm{c}} \mathrm{dm}^{-3} ; \mathrm{H}+\mathrm{Al}$ (acetato de $\mathrm{Ca}$ $\left.0,5 \mathrm{~mol} \mathrm{~L}^{-1}\right) 3,14 \mathrm{cmol}_{\mathrm{c}} \mathrm{dm}^{-3}$; SB10,05 $\mathrm{cmol}_{\mathrm{c}} \mathrm{dm}^{-3}$, CTC $13,19 \mathrm{cmol}_{\mathrm{c}} \mathrm{dm}^{-3} ; \mathrm{V} \mathrm{73,19 \%}$, Matéria orgânica (Método Boyocus) $15,04 \mathrm{~g} \mathrm{dm}^{-3}$; Cu 27,90mg dm $\mathrm{m}^{-3}$; $\mathrm{Zn} \mathrm{23,40mg}$ $\mathrm{dm}^{-3}$; Mn 209,00mg dm${ }^{-3}$; Fe 31,20 $\mathrm{mg} \mathrm{dm}^{-3}$.

As coletas de amostras ocorreram em um campo de Tifton 85 , que é um híbrido do gênero Cynodon, oriundo do cruzamento do cultivar 'Tifton 68' com uma introdução PI-290884, proveniente da África do Sul. Esse híbrido é destinado somente para a produção de feno que recebe periodicamente biofertilizante, proveniente da criação de suínos na quantidade de $150 \mathrm{~m}^{3} \mathrm{ha}^{-1}$ ano $^{-1}$, sempre aos 7 dias de rebrota, após o corte para fenação. $\mathrm{Na}$ análise do biofertilizante por espectrometria de absorção atômica (EAA), modalidade chama, detectou-se: $\mathrm{N}$ : 0,09 $\mathrm{g} \mathrm{kg}^{-1}$; $\mathrm{K}: 1,18 \mathrm{mg} \mathrm{kg}^{-1}$; Ca: $0,21 \mathrm{mg} \mathrm{kg}^{-1}$; $\mathrm{Mg}$ : 0,03mg kg-1; Cu: 0,07 $\mathrm{mg} \mathrm{kg}^{-1}$; Zn: $0,36 \mathrm{mg} \mathrm{kg}^{-1}$; Mn: 0,10 $\mathrm{mg} \mathrm{kg}^{-1}$; Fe: $0,96 \mathrm{mg} \mathrm{kg}^{-1}$; P: não detectado.

$\mathrm{O}$ delineamento experimental adotado foi em blocos casualizados em função da declividade da área com parcelas subdivididas no tempo, com quatro locais de coleta (solo, parte aérea da planta, raiz e material vegetal morto) compondo as parcelas principais e quatro tempos de avaliação compondo as subparcelas. As amostragens para solo, raiz e material vegetal morto foram realizadas aos $15 ; 22 ; 29$ e 36 dias de rebrota e as amostragens para parte aérea da planta foram realizadas aos 15; 22; 29 e 36 dias de rebrota, no momento do enfardamento e com 30 dias de armazenamento, com cinco repetições.

Para a realização das análises microbiológicas, as amostras da parte aérea foram coletadas com o auxílio de um cutelo a $5 \mathrm{~cm}$ do solo. Dessa mesma área onde se encontrava a parte aérea do Tifton 85, foram retiradas as raízes, o material vegetal morto (coleta do material senescente acima do solo) e as amostras de solo a $5 \mathrm{~cm}$ de profundidade. As amostragens da parte aérea da planta foram realizadas aos $15 ; 22 ; 29$ e 36 dias de rebrota, no momento do enfardamento ( 38 dias de rebrota) e com 30 dias de armazenamento, enquanto as amostragens para solo, raiz e material vegetal morto foram aos $15 ; 22 ; 29$ e 36 dias de início da rebrota.

$\mathrm{O}$ corte da forrageira na área experimental foi realizado com a utilização de uma segadeira condicionadora tratorizada, com batedores de dedos livres de ferro, em altura residual de $5 \mathrm{~cm}$ do solo. A forragem permaneceu sobre o campo por 48 horas para desidratação até atingir a matéria seca (MS) ideal para enfardamento, ou seja, acima de $80 \%$ de MS. Foram confeccionados fardos retangulares com peso médio de $10 \mathrm{~kg}$, os quais foram armazenados em galpão fechado, protegido de chuva e com aeração através de pequenas janelas.

Os fungos foram isolados por indução de crescimento do micélio em meio de cultivo BDA por esporulação induzida ou por isolamento direto dos sinais (estruturas reprodutivas) do patógeno a partir das amostras coletadas (MENEZES et al., 1997). As diluições variaram de $10^{-1}$ a $10^{-5}$, sendo consideradas para contagem as placas de Petri que apresentaram entre 30 e 300UFC (Unidade Formadora Colônia). 
Após o período de incubação de sete dias, as colônias foram contadas, utilizando-se um contador colônias Quebec. Os resultados de contagem de população de fungos neste ensaio foram expressos em log de UFC $\mathrm{g}^{-1}$ de amostras de solo, material vegetal morto, raiz e parte aérea.

A partir de observação em microscópio estereoscópico, foram preparadas lâminas semipermanentes de todas as estruturas fúngicas encontradas, tanto no material sintomático como em meio de cultivo. Essas estruturas foram transferidas, com auxílio de agulha ou estilete para lâmina de microscopia com corante azul de metila em lactofenol, cobertas com lamínula, seladas com esmalte e observadas em microscópio ótico para identificação dos gêneros de fungos, com auxílio de chaves de identificação (BARNETT \& HUNTER, 1987).

Os dados referentes à contagem da população total de fungos foram submetidos à análise de variância e as médias foram comparadas pelo teste de Tukey em nível de 5\% de probabilidadede erro. $\mathrm{Na}$ contagem e identificação dos gêneros dos fungos referentes a cada parte da planta, foram calculadas as médias e essas submetidas à análise descritiva.

\section{RESULTADOS E DISCUSSÃO}

$\mathrm{Na}$ contagem total de fungos (Log UFC $\mathrm{g}^{-1}$ ), houve efeito significativo nas diferentes partes da planta e solo durante o desenvolvimento do capim Tifton $85(\mathrm{P}<0,05)$. Observou-se maior população de fungos no material vegetal morto seguido pelo solo, parte aérea e raiz, respectivamente (Tabela 1). Isso mostra a importância de se estabelecer uma altura para corte ideal da planta forrageira para evitar a contaminação da forrageira por microrganismos indesejáveis, presentes no solo e no material vegetal morto. $\mathrm{O}$ fornecimento de material com alta concentração de fungos e a exposição a esporos fúngicos pode ser prejudicial à saúde dos animais, bem como às pessoas que manuseiam essas forrageiras, devido à produção de toxinas, principalmente aquelas relacionadas aos fungos patogênicos (MUCK \& SHINNERS, 2001). As micotoxinas produzidas durante a esporulação dos fungos contaminam os animais que consomem alimentos contaminados. Dessa forma, são transferidas para os seus produtos (leite e carne) e, consequentemente, prejudicam a saúde humana (BRUERTON, 2001).

Embora animais saudáveis tendem a detoxificar muitas micotoxinas às quais estão expostos, a questão dos resíduos no leite e em tecidos animais não deve ser ignorada por produtores e consumidores, em virtude dos possíveis danos a saúde humana (JOBIM et al., 2001). O maior aumento da população de fungos na parte aérea nos primeiros dias de rebrota, observados neste trabalho, pode ser consequência da aplicação recente do dejeto que eleva a umidade superficial da planta, criando um ambiente favorável ao desenvolvimento de alguns gêneros de fungos.

Observou-se que a população de fungos de maior ocorrência na parte aérea do capim Tifton 85, durante o período experimental, foram dos gêneros Penicillium, Cladosporium e Aspergillus (Figura 1), sendo observada uma maior ocorrência do gênero Aspergillus, principalmente no feno, após 30 dias de armazenamento. O aumento na população de fungos dos gêneros Aspergillus e Penicillium está relacionado com o teor de umidade no feno durante o armazenamento (REIS et al., 1997). Os fungos de armazenamento, como o gênero Aspergillus, podem servir como indicador biológico das condições de armazenamento. Sua quantificação em forragens conservadas é fundamental, devido a representar um potente produtor de micotoxinas (MOSER, 1995),

Tabela 1 - População de fungos (Log UFC g $^{-1}$ ) do capim Tifton 85 adubado com biofertilizante suíno nas diferentes partes da planta e solo, durante seu desenvolvimento.

\begin{tabular}{|c|c|c|c|c|}
\hline \multirow{2}{*}{ Parte da planta } & \multicolumn{4}{|c|}{--Dias de rebrota- } \\
\hline & 15 & 22 & 29 & 36 \\
\hline Parte aérea & $3,08 b$ & $3,11 b$ & $2,74 \mathrm{bc}$ & $2,74 \mathrm{bc}$ \\
\hline Material vegetal morto & $5,23 a A$ & $4,38 \mathrm{aAB}$ & $3,56 a b B$ & $4,86 a A$ \\
\hline Raiz & $1,94 \mathrm{c}$ & $2,20 b$ & $1,68 c$ & $1,89 c$ \\
\hline Solo & $4,09 b$ & $3,20 b$ & $4,11 a$ & $3,51 b$ \\
\hline CV1(\%) & \multicolumn{4}{|c|}{46,55} \\
\hline CV2(\%) & \multicolumn{4}{|c|}{50,08} \\
\hline
\end{tabular}




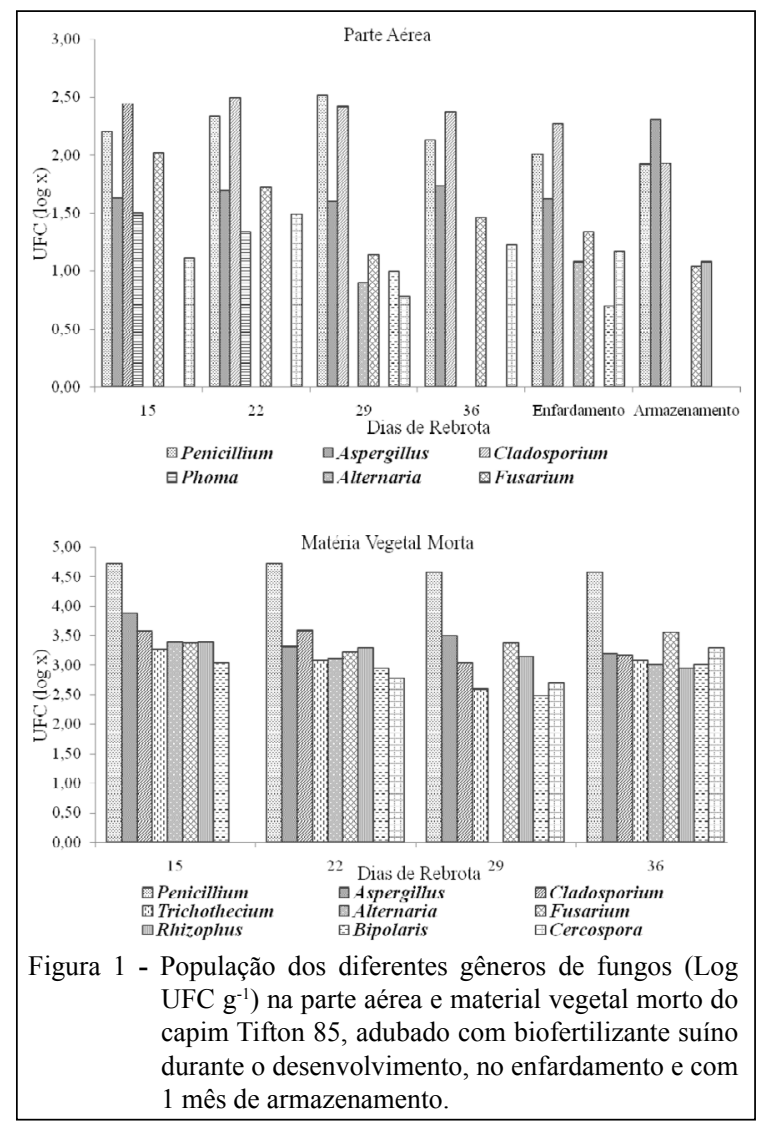

ocorrendo com maior frequência em ambientes quentes e úmidos.

Alterações acentuadas podem ocorrer na população de fungos com o processo de fenação, havendo diminuição daqueles gêneros típicos de campo, como Fusarium e Cladosporium, e aumento da população de gêneros como Aspergillus e Penicillium, de maior ocorrência no armazenamento (HLODVERSSON \& KASPERSSON, 1986). De maneira geral, a população de microrganismos é fortemente afetada pelo conteúdo de umidade e pela temperatura registrados durante o armazenamento, e o efeito desses fatores é difícil de separar no contexto prático (ROBERTS, 1995).

O material vegetal morto apresentou uma grande variedade de gêneros de fungos (Figura 1), sendo que o gênero Penicillium foi o mais frequente entre os gêneros Aspergillus, Cladosporium, Trichothecium, Alternaria, Fusarium, Rhizophus, Bipolaris e Cercospora. A alta população do gênero Penicillium pode levar a uma maior produção de micotoxinas, dependendo das condições ambientais e da espécie presente, sendo que essas micotoxinas afetam tanto a saúde animal quanto a humana.
Esses resultados corroboram os obtidos por LACEY (1975), que observou uma grande variedade de fungos no material morto ou senescente, derivados do solo e do ar, crescendo especificamente em gramíneas nativas na forma saprófita. Sabendo-se que o gênero Cladosporium é considerado saprófita, NEPOMUCENO et al. (2008) afirmam que a presença de fungos em forrageiras pode estar relacionada ao parasitismo, refletindo em fitopatologias ou saprofitismo. Neste último caso, pode ocorrer diminuição do consumo da forrageira pelos animais, devido a rejeições e depreciação das forragens.

Nas amostras de raízes do Tifton 85 , os gêneros de fungos que se desenvolveram foram Penicillium, Aspergillus, Cladosporium e Bipolaris (Figura 2). O gênero Penicillium, juntamente com o gênero Aspergillus, são capazes de crescer nos mais diversos tipos de habitats (MACHADO, 2006). O gênero Bipolaris é um agente etiológico da helmintosporiose, mais conhecida como mancha marrom das folhas, carvão do nó, ponto preto das sementes (TINLINE, 1988). Ela também pode causar a podridão comum das raízes, mostrando que qualquer parte da planta pode ser alvo da infecção pelo fungo (CARISSIMI, 2006). Mesmo que os cereais de inverno, como trigo e aveia, sejam os principais hospedeiros, o fungo já foi isolado em leguminosas, gramíneas,

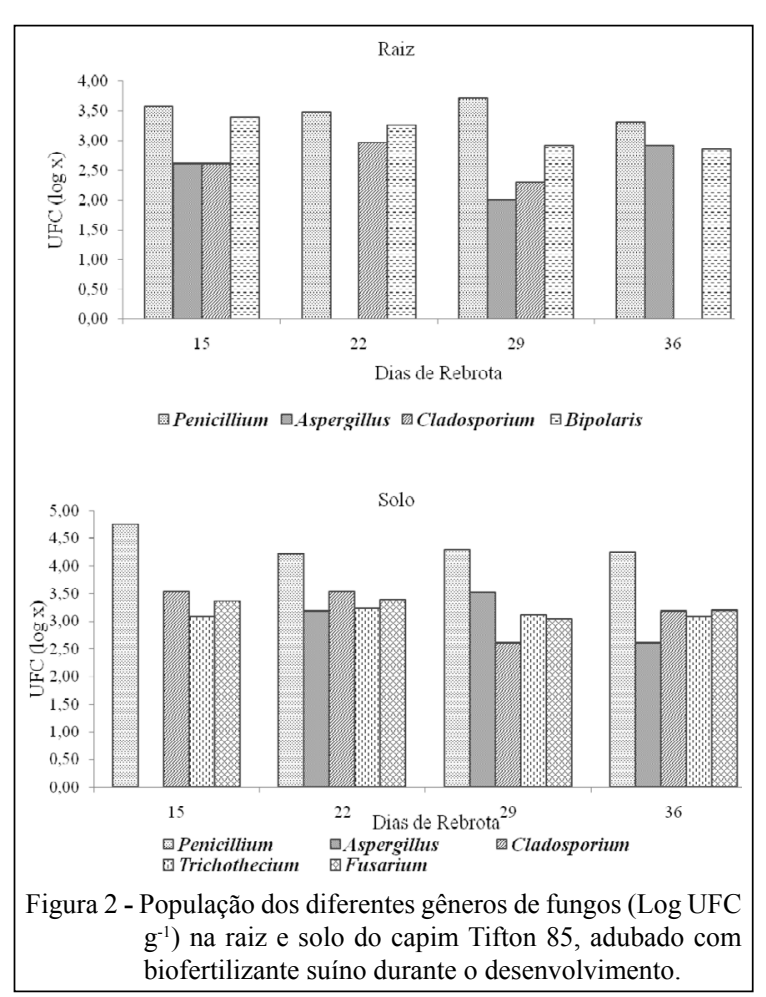

Ciência Rural, v.46, n.3, mar, 2016. 
sementes oleaginosas, milho, girassol e tomate em condições experimentais (DUCZEK et al., 1996).

Os microrganismos do solo incluem bactérias, fungos, protozoários e algas, sendo os fungos os que geralmente predominam entre os microrganismos do solo, podendo ser simbiontes de plantas, patogênicos de plantas e animais (MACHADO, 2006). Existe uma grande diversidade de população de fungos encontrados no solo, mas os gêneros mais frequentemente isolados do solo são: Mucor, Penicillium, Trichothecium e Aspergillus, seguidos por Rhizopus, Zygorhynchus, Fusarium, Cephalosporium e Verticillium (ROITMAN et al., 1991; AUER et al., 2007). No presente estudo, observou-se, em amostras do solo da área experimental (Figura 2), o desenvolvimento de populações de fungos do gênero Penicillium, Aspergillus, Cladosporium, Trichothecium e Fusarium.

Fungos do gênero Penicillium, abundante na área amostrada, são de um gênero cosmopolita envolvido na decomposição de matéria orgânica no solo e antagonista de espécies de fitopatógenos (GOMEZ et al., 2007). A predominância da população desse gênero pode estar diretamente relacionada à produção de metabólitos secundários, ou indiretamente, pela competição nutricional, maior produção de esporos e maior capacidade de crescimento em meio de cultura (CARVALHO et al., 2008).

\section{CONCLUSÃO}

$O$ gênero de fungo de maior ocorrência numa área de produção de feno de capim Tifton 85 , adubada com biofertilizante suíno, nas condições estudadas e época do ano, é o gênero Penicillium, e a maior incidência e o número de população de fungos ocorrem no material vegetal morto e solo.

\section{AGRADECIMENTOS}

Ao Conselho Nacional de Desenvolvimento Científico e Tecnológico (CNPq processo nº $471834 / 2013-0)$, pelo financiamento do projeto.

\section{REFERÊNCIAS}

AUER, C.G. et al. Decomposição fúngica de acículas em plantios de Pinus. Pesquisa Florestal Brasileira, Colombo, n.54, p.127138, 2007. Disponível em: <http://pfb.cnpf.embrapa.br/pfb/index. php/pfb/article/view/137/97>. Acesso em: 20 fev. 2014.

BARNETT, H.L. et al. Illustrated genera of imperfect fungi. New York: Macmillan Publishing, 1987. 218p.
BRUERTON, K. Finding practical solutions to mycotoxins in commercial production: a nutritionist's perspective. In: ALLTECH'S ANNUAL SYMPOSIUM, 17., 2001, Sorrento, Australian. Proceedings... Australian: Alltech, 2001. p.161-168.

CARISSIMI, M. Estudo da atividade antifúngica de Bacillus E. 164 contra Bipolaris sorokiniana. 2006. 71f. Dissertação (Mestrado em Microbiologia Agrícola e do Ambiente Microbiologia do Controle Biológico) - Curso de Pós-graduação em Microbiologia Agrícola e do Ambiente, Universidade Federal do Rio Grande do Sul, RS.

CARVAlHO, V.G. et al. Comunidades de fungos em solo do cerrado sob vegetação nativa e sob cultivo de soja e algodão. 2008. 62f. Dissertação (Mestrado em Microbiologia Agrícola) Curso de Pós-graduação em Microbiologia Agrícola, Universidade Federal de Lavras, MG.

DOMINGUES, J.L. Use of conserved roughage in the horse feeding. Revista Brasileira de Zootecnia, v.28, supl. esp., p.259-269, 2009. Disponível em: $<$ http://www.scielo.br/scielo.php?script=sci_arttex t\&pid=S1516-35982009001300026 $>$. Acesso em: 20 jul. 2014. doi: 10.1590/S1516-35982009001300026.

DUCZEK, K.L.J. et al. Sporulation of Bipolaris sorokiniana on the crowns of crop plants in Saskatchewan. Canadian Journal of Plant Science, v.76, p.861-867, 1996. Disponível em: <http:// pubs.aic.ca/doi/pdf/10.4141/cjps96-146>. Acesso em: 15 jul. 2014. doi: $10.4141 / \operatorname{cjps} 96-146$.

FREIRE, F.C.O. et al. Micotoxinas: importância na alimentação e na saúde humana e animal. Fortaleza: EMBRAPA Agroindústria Tropical, 2007. 48p. (Documento 110).

GOMEZ E. et al. Fungal abundance and distribution as influenced by clearing and land use in a vertic soil of Argentina. Biology and Fertility of Soils, v.43, p.373-377, 2007. Disponível em: $<$ http://www.researchgate.net/publication/226221532_Fungal_ abundance_and_distribution_as_influenced_by_clearing_and land_use_in_a_vertic_soil_of_Argentina>. Acesso em: 23 jul.

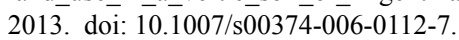

HLODVERSSON, R. et al. Nutrient losses during deterioration of hay in relation to changes in biochemical composition and microbial growth. Animal Feed Science and Technology, v.15, n.2, p.149165, 1986. Disponível em: <http://www.animalfeedscience.com/ article/0377-8401(86)90022-2/abstract>. Acesso em: 23 jul. 2014. doi: 10.1016/0377-8401(86)90022-2.

JOBIM, C.C. et al. Methodological advances in evaluation of preserved forage quality. Revista Brasileira de Zootecnia, v.36, supl. esp., p.101-119, 2007. Disponível em: <http://www.scielo.br/ scielo.php?script=sci_arttext\&pid=S1516-35982007001000013>. Acesso em: 28 jul. 2014. doi: 10.1590/S1516-35982007001000013.

JOBIM, C.C. et al. Qualidade Sanitária de grãos e de forragens conservadas "versus" desempenho animal qualidade de seus produtos. In: SIMPÓSIO SOBRE PRODUÇÃO E UTILIZAÇÃO DE FORRAGENS CONSERVADAS, 2001, Maringá, PR. Anais... Maringá: Universidade Estadual de Maringá/Centro de Ciências Agrárias /Departamento de Zootecnia, 2001. 319p. p.242-261.

LACEY, J. Potential hazards to animal and man from microorganisms in fodders and grain. Transactions of the British Mycological Society, v.65, n.2, p.171-184, 1975. Disponível em: <http://www.sciencedirect.com/science/article/pii/ 
S0007153675800015>. Acesso em: 21 jul. 2014. doi: 10.1016/ S0007-1536(75)80001-5.

MACHADO, A.P.S. Uso de técnicas de detecção rápida de fungos filamentosos na água. 2006. 64f. Dissertação (Mestrado em Tecnologia do Ambiente) - Escola Superior de Engenharia da Universidade do Minho.

MENEZES, M. et al. Guia prático para fungos fitopatogênicos. Recife: UFRPE, 1997. 106p.

MUCK, R.E.; SHINNERS, K.J. Conserved forages (silage and hay): Progress and priorities. In: INTERNATIONAL GRASSLAND CONGRES, 19., 2001. São Pedro, SP. Anais... São Pedro: Brazilian Society of Animal Husbandry. 2001. p.753-762.

NEPOMUCENO, D.D. et al. Associação de fungos a cinco espécies de leguminosas forrageiras. In: ENCONTRO LATINO AMERICANO DE INICIAÇÃO CIENTÍFICA, 12., e ENCONTRO LATINO AMERICANO DE PÓS-GRADUAÇÃO, 8., São José dos Campos, SP. Anais... São José dos Campos: Universidade do Vale do Paraíba, 2008. p.1-3.

REIS, R.A. et al. Effects of the ammoniation on the occurrence of fungi, chemical composition, and in vitro digestibility of grama seda (Cynodon dactylon (L.) Pers.) hays. Revista Brasileira de
Zootecnia. v.26, n.3, p.454-460, 1997. Disponível em: <http:// www.sbz.org.br/revista/artigos/66.pdf>. Acesso em: 28 jul. 2014.

REIS, R.A. et al. Nutritive value of ammoniated coast cross (Cynodon dactylon L. Pers) hay. Ars Veterinária, v.19, n.2, p.143-149, 2003. Disponível em: <http://www.arsveterinaria.org. br/arquivo/2003/v.19,\%20n.2,\%202003/143-149.pdf>. Acesso em: 25 jul. 2014.

REIS, R.A. et al. Produção qualidade e aspectos sanitários de fenos. Jaboticabal: FCAV/UNESP, 2008. Disponível em: $<$ http://www.fcav.unesp.br/Home/departamentos/zootecnia/ ANACLAUDIARUGGIERI/feno_palestra_botucatu.pdf>. Acesso em: 25 jul. 2014.

ROBERTS, C.A. Microbiology of stored forages. In: MOORE, K.J. et al. Post-harvest physiology and preservation of forages. Madison: American Society of Agronomy 1995. p.21-38.

ROITMAN, I. et al. Tratado de microbiologia. São Paulo: Manole, 1991. v.2. $126 \mathrm{p}$.

SANTOS, H.G. et al. Sistema brasileiro de classificação de solos. Brasília: EMBRAPA Solos, 2013. 353p.

TINLINE, K.D. Cochliobolus sativus, a pathogen of wide host range. Advances in Plant Pathology, v.6, p.113-122, 1988. 